\title{
CLASSIFICAÇÃO DE AMBIENTES TÉRMICAMENTE HOMOGÊNEOS PARA ESTUDOS DE CLIMA NA CAMADA DO DOSSEL URBANO - METODOLOGIA E APLICAÇÃO À CIDADE DE PELOTAS/RS
}

\author{
COLLISCHONN, Erika - ecollischonn@gmail.com.br \\ Universidade Federal de Pelotas \\ MATTOS, Gil Passos de - gilpassosm@hotmail.com \\ Universidade Federal de Pelotas
}

\begin{abstract}
Resumo: O "perímetro urbano" que, segundo a lei vigente no Brasil, é a linha que separa o urbano do rural, não representa esta distinção de modo satisfatório, já que interesses econômicos, políticos e tributários muitas vezes prevalecem na sua demarcação. Além disso, o espraiamento do fenômeno urbano tornou mais indefinido o limite entre o "urbano" e o "rural" e também mais difícil de ser percebido, exigindo novos recortes espaciais intermediários mais condizentes com esta nova realidade, também para a investigação de ilhas de calor. Neste trabalho, avaliamos na literatura sobre clima urbano, propostas de classificação de unidades climáticas homogêneas do ponto de vista das características térmicas do ar próximo à superfície, justificamos porque escolhemos a proposta de Steward e Oke (2009), adaptamos esta classificação para que se tornasse aplicável ao perímetro urbano de Pelotas/RS e, finalmente, apresentamos o processo de identificação das potenciais Unidades climáticas diferenciadas no perímetro urbano desta cidade, a partir de imagem de satélite de alta resolução espacial num sistema de informações geográficas.
\end{abstract}

Palavras chave: Perímetro urbano - Unidades climáticas - sensoriamento remoto

DEFINING POTENTIAL "CLIMATIC URBAN UNITIES" IN THE URBAN CANOPY LAYER METHODOLOGY AND ITS APPLICATION IN PELOTAS/RS

Abstract: "Urban area", according to the Brazilian law, is the line that separates cities and towns from rural areas. This distinction is not so satisfactory, because economic, political, and tax-(related) interests often prevail in its demarcation. Moreover, the sprawl of the urban phenomenon caused the boundary between "urban" and "rural" areas to be less defined and also more difficult to perceive, requiring a new and more purposeful classification of sites more consistent with this new reality. The best setting is also crucial to the investigation of heat islands. In this study, we made an evaluation based on urban climate literature propositions of "thermal climate zones" for classifying urban heat islands measurement sites, we justified why we chose the proposal of Steward and Oke (2009), we adapted this classification to become applicable to the urban area of Pelotas / RS, and finally presented the process of identifying potential climate units within this urban area using high spatial resolution satellite imagery in a geographic information system.

Keywords: Urban area - Urban Clime Zones - Remote sensing

\section{Introdução}

Nos estudos de clima urbano realizados por geógrafos é fundamental, como desde 1975 vem ensinando Monteiro, que paralelamente ou em complementaridade as análises meteorológicas da atmosfera sobre as cidades, se adentre no interior delas, "tomando-as como 'fato geográfico', em sua real estruturação físico-natural de ambiente altamente 'derivado' pelo homem sob uma dinâmica funcional conduzida pelos condicionamentos econômicos" (MONTEIRO, 1990a, p.9). Isto porque o que o geógrafo quer compreender é a transformação de energia num jogo integrado entre o ar atmosférico e o ambiente urbano edificado pelo homem.

Em países como Alemanha, Áustria, Suíça e Portugal é prática freqüente a preparação de mapas de análise, de síntese e de avaliação climática, como apoio ao processo de planejamento urbano. Os relatórios que resultam destes estudos iniciam em sua maioria com mapas, nos quais se delimita áreas que potencialmente apresentem "climas locais homogêneos", condicionados pela ocupação do solo e morfologia urbana e por condições de ventilação particulares, ou seja, põe a tônica na necessidade de descrever adequadamente as propriedades de áreas urbanas que afetam a atmosfera próxima a superfície. Cada área destas condicionará de forma diferenciada a vida e as atividades humanas e exigirá, portanto, diferentes medidas para reduzir os impactos negativos e potenciar as características positivas do clima urbano.

No projeto "Clima urbano/conforto térmico e condições de vida na cidade de Pelotas/RS", em desenvolvimento, consideramos primordial dispor de mapeamentos pormenorizados, tanto das características do sítio quanto do uso e ocupação da terra. Ainda que a Prefeitura Municipal de Pelotas tenha preparado bons mapas para a realização do Plano Diretor Municipal de 2008, informações inerentes a relação aquecimento-resfriamento do ar não foram aí consideradas. Assim, na parte do projeto que apresentamos neste trabalho, avaliamos, na literatura sobre clima urbano, propostas de classificação de unidades homogêneas do ponto de vista das características térmicas do ar próximo à 
superfície, posteriormente, adaptamos uma destas classificações para que se tornasse aplicável a nossa área de estudo e, por fim, apresentamos a metodologia utilizada para identificação das potenciais Unidades Climáticas diferenciadas no perímetro urbano de Pelotas num sistema de informações geográficas.

Nos periódicos científicos sobre o tema lê-se, freqüentemente, a expressão "zonas climáticas urbanas" para estas unidades, preferimos não fazer uso dela, pois julgamos que o termo "Zona Climática" já é consagrado para a divisão dos macroclimas da terra (faixas entre paralelos); deste modo utilizamos "Unidades Climáticas", como fizeram Tarifa e Armani (2001). Adicionamos o adjetivo "potencial", porque avaliamos que, para chegarmos às Unidades Climáticas de fato, ainda será preciso avaliar a dimensão das relações entre os controles climáticos urbanos (uso do solo, fluxo de veículos, densidade populacional, densidade das edificações, orientação e altura das edificações, áreas verdes, represas, parques e emissão de poluentes) e os atributos (temperatura da superfície, do ar, umidade, insolação, radiação solar, ventilação). Esta será uma próxima etapa de pesquisa.

\title{
Diretrizes teórico-metodológicas
}

O enquadramento teórico para conduzir a análise nesse trabalho remete à tese de doutorado de Mendonça (1995, in Monteiro e Mendonça, 2003) que propõe uma metodologia para o estudo do clima urbano de cidades médias; porém, consideramos de uso mais direto as diretrizes estratégicas propostas por Monteiro (1990b, p. 61-79), Oke (2006) e Steward e Oke (2009) para identificar áreas diferenciadas dentro do perímetro urbano de Pelotas que exerçam maior ou menor efeito na atmosfera urbana. Essas unidades devem ser levadas em conta, para a seleção de locais para a coleta de dados de clima urbano e incorporadas na descrição da configuração da estação ou posto de coleta.

Com certeza, um primeiro aspecto que se deve considerar é o que Monteiro denomina de carater geo-ecológico do sítio no qual se encontra a cidade, manifesto nas unidades morfológicas que nele se distinguem. Esse caráter, segundo Monteiro, se evicencia "[...] não apenas pelas formas primitivas (ou naturais)mas também pelas derivações, acréscimos (represas, [canais], aterros, etc) e supressões (arrasamento de morros, deflorestamentos, etc)" (1990a, p. 68).

Oke (2006, p.9) destaca que no processo de compreensão do efeito do urbano na "camada de dossel", que se estende do solo até o nível das coberturas dos edifícios, deve-se avaliar: a estrutura urbana (a dimensão das edificações e o espaços entre elas, a largura das vias e o espaçamento entre elas), a cobertura da superfície (construída, pavimentada, com cobertura vegetal, solo descoberto, água), o tecido urbano (resultante do processo de expansão do fenômeno urbano, suas continuidades e descontinuidades) e o metabolismo urbano (água, calor e poluentes devido à atividade humana). Proposições semelhantes para identificação de padrões já tinham sido feitas por outros especialistas em clima urbano, mas Monteiro (1990a, p.67), por conhecer melhor a realidade das cidades brasileiras, acrescenta:

\begin{abstract}
Em se tratando de cidades brasileiras é necessario considerar nestes padrões de edificacões aquilo que e urn fato pertinente a nossa realidade socio-economica, ou seja, as vastas áreas onde a pobreza do urbano deixa nele indelevelmente marcada a "sub-habitação". Assim na caracterização de nossos espaços urbanos nao podemos deixar de considerar as áreas de edificação não planejada (expontanea, informal, clandestina) quanto aquelas formas mais agudas representadas pelas "favelas". Além de marcas indisfarçáveis dos problemas sociais estas edificações constituem-se em padrões diferenciados do ponto de vista "físico". Seja pelos materiais de construção, pela coloração, densidade, eles sem dúvida representam padrões de ambiente edificados inerentes a nossa realidade urbana e, como tal, nao podem ser ignorados na análise do clima das nossas cidades.
\end{abstract}

Assim, a abordagem do clima urbano requer um conhecimento geográfico da cidade e um embasamento cartográfico que permita a divisão da cidade em partes com características relativamente homogêneas, como etapa primeira e fundamental de estudo (MENDONÇA, 2003, p.99).

Há poucos sistemas de classificação da paisagem em escala local na literatura sobre clima urbano. Em 1978, Auer (apud STEWARD e OKE, 2009) propôs um sistema de 
classificação utilizando critérios de uso da terra e cobertura vegetal. Em 1990, Ellefsen (apud OKE, 2006) desenvolveu um sistema de classificação na escala bairro, com base na morfologia de construção, na configuração de ruas e nos materiais de construção utilizados nas grandes cidades norte-americanas. Posteriormente, esta classificação foi aprimorada no que se refere à rugosidade de terreno urbano e rural, com base na altura e densidade de elementos de superfície (por exemplo, edifícios, árvores, plantas). Em 2004, Oke projetou para a Organização Meteorológica Mundial um sistema de classificação climática simples, distinguindo padrões urbanos organizados em ordem aproximadamente decrescente quanto a sua capacidade em impactar o clima local (OKE, 2006, p. 11). Incorporando características dos trabalhos anteriores, seu sistema discretiza no terreno urbanizado áreas homogêneas denominadas "zonas climáticas urbanas". Ele distingue sete padrões diferenciados com base na rugosidade, tipo de cobertura, impermeabilização e usos. Enquanto neste esquema falta o padrão relativo às áreas de sub-habitação, mais comum em cidades do Terceiro Mundo ele identifica um padrão que não se aplica a uma cidade média como Pelotas, que é a dos arranha-céus do Centro de Negócios (CBD - Central Business District).

Em trabalho mais recente, Steward e Oke (2009) criaram uma classificação centrada na paisagem (Figura 1). Partindo da avaliação global do conjunto da paisagem os autores a decompõem, num primeiro momento, partindo do princípio da modificação da superfície, isto é, o grau em que o aspecto técnico-cultural se sobrepõe à superfície físico-natural. A marca da técnica se manifesta pela substituição da cobertura da superfície natural (por exemplo, florestas, solos, gramíneas) por uma cobertura "não nativa" (por exemplo, edifícios, estradas, lavouras). A divisão da paisagem a partir deste princípio produz quatro categorias: urbana, agrícola, natural e mista. Integram a categoria "Urbana" as áreas fortemente alterados pela construção de edifícações, ruas e outras redes; a categoria "agrícola" as áreas alteradas pelo cultivo dos solos e pela criação de animais; na categoria "natural" se inserem paisagens que preservam uma cobertura nativa da superfície; e se adiciona ainda à hierarquia a categoria "mista" que representa a mistura do urbano, do agrícola e/ou do natural da paisagem. Cada uma destas categorias foi subidividida em unidades menores (de dezenas a centenas de metros) com propriedades de superfície específicas na interação com a camada de dossel urbano. Essas propriedades incluem: (1) altura da rugosidade superficial (alta, média ou baixa), o que influencia regimes de fluxo do ar acima do solo, (2) fração de superfície impermeável (alta ou baixa), que divide a energia na forma sensível (aquecimento) ou latente (resfriamento); (3) fator de visão do céu (alta ou baixa), o que influencia resfriamento da superfície por radiação; (4) o desempenho térmico (alto ou baixo), que modula os ciclos de aquecimento e arrefecimento de solos e materiais de construção, (5) albedo (alto ou baixo), o que influencia a absorção de calor de superfície, e (6) fluxo de calor antropogénico (alto, baixo ou nulo) que contribui com calor de combustão para o balanço da energia superficial. 


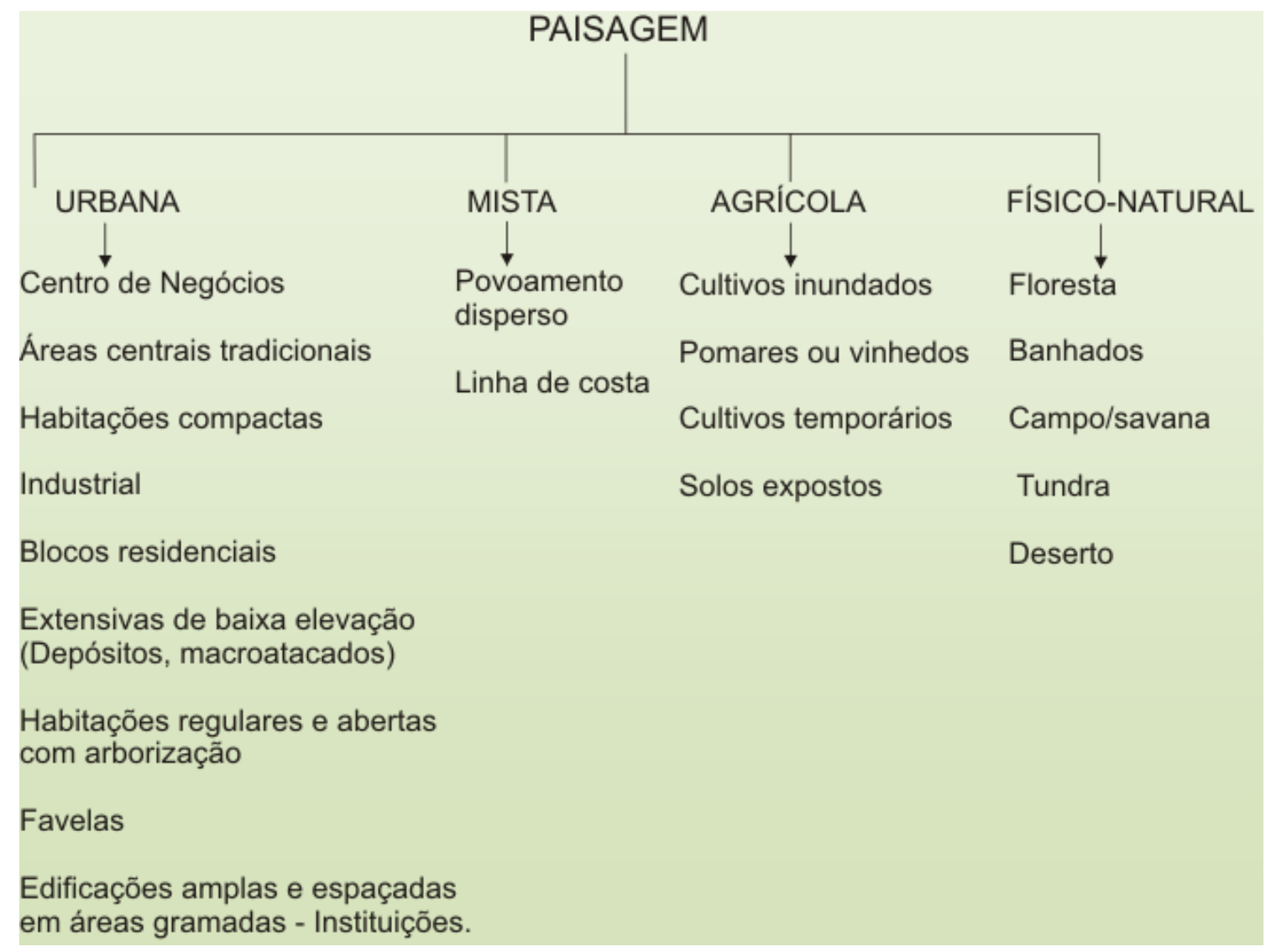

Figura 1

\section{Divisão lógica das classes no universo da paisagem}

(Fonte: STEWARD e OKE, 2009, adaptado).

Este sistema foi o mais consistente que encontramos quanto à identificação de unidades universalmente reconhecíveis e, ao mesmo tempo, afigurava-se aplicável utilizando dados de sensoriamento remoto, uma vez que, cada uma das 20 unidades definidas por Steward e Oke (2009) é individualmente descrita e ilustrada em folhas de dados padronizados. Estas folhas de dados servem como chaves de interpretação visual de imagens de sensores remotos, auxiliando os usuários de sistemas de informações geográficas a alocarem com maior objetividade as classes adequadas. Cada uma delas inclui a definição da unidade, desenhos de computador, fotografias oblíquas, e caracterização das propriedades térmicas de superfície.

Um grande avanço foi incorporado aos estudos de classificação do uso e cobertura da terra em áreas urbanas com o lançamento dos satélites Ikonos II em 1999, QuickBird-II em 2001, OrbView III em 2003, Cbers 2B em 2007, GeoEye em 2008 e mais WorldViewII em 2009, que produzem imagens de alta resolução espacial. Assim, deixou de haver insuficiência no uso de sensoriamento remoto orbital para o estudo da complexidade espacial do fenômeno urbano. A disponibilidade destes sensores tornou possível discriminar melhor os alvos na superfície, revolucionando os estudos intra-urbanos pelo avanço na precisão das informações geradas.

\section{Caracterização da área de estudo}

Pelotas é uma cidade média de 333.120 habitantes (IBGE, 2010), localizada a $31^{\circ} 45^{\prime} \mathrm{S}$ e $52^{\circ} 20^{\prime \prime} \mathrm{W}$ (Figura 2), às margens do Canal de São Gonçalo, curso que liga as lagoas dos Patos e Mirim no sul do Rio Grande do Sul. 


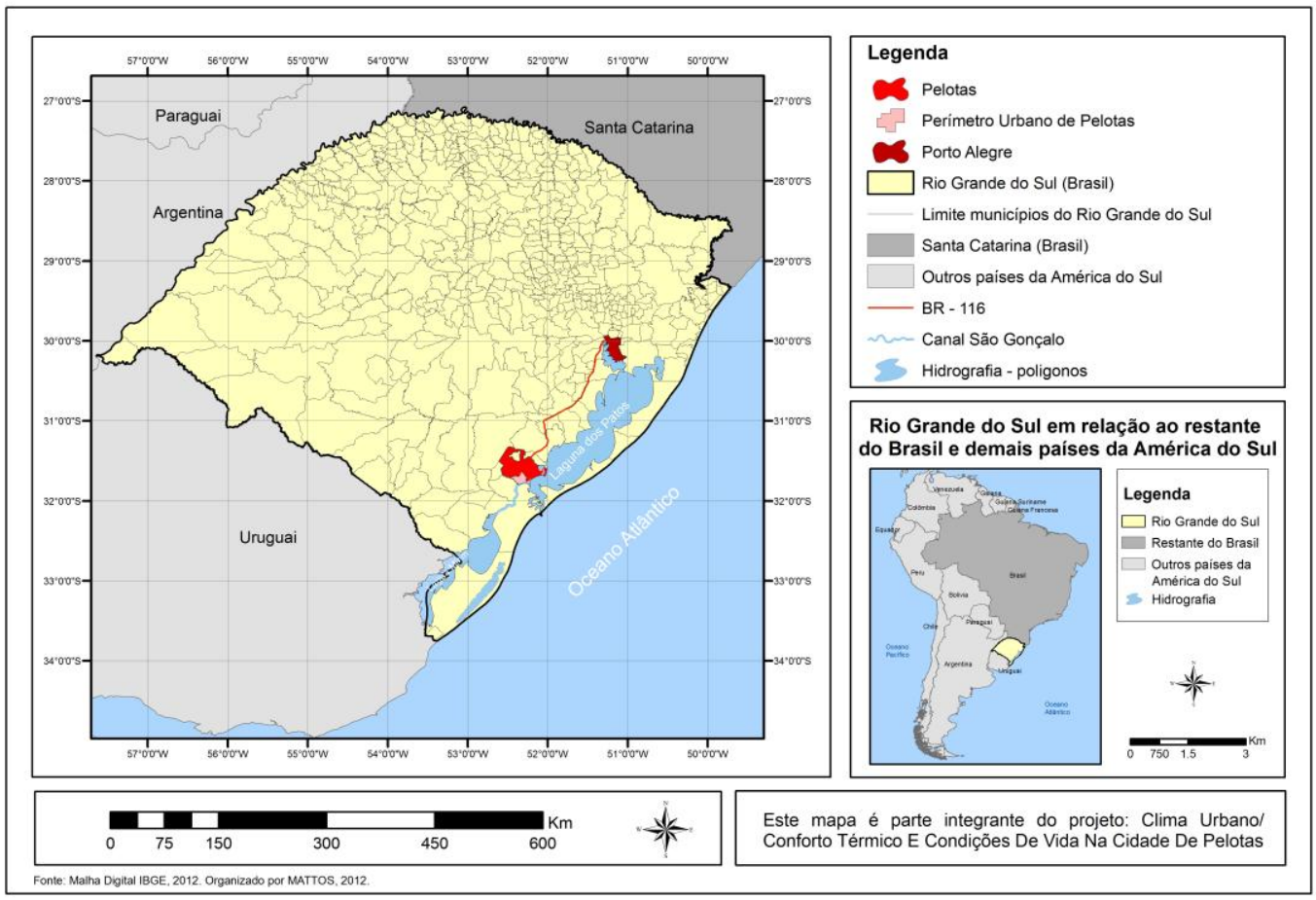

Figura 2

\section{Localização de Pelotas/RS.}

O perímetro urbano se encontra em área plana e de baixa altitude (Figura 3). A proximidade da Lagoa dos Patos e do Canal de São Gonçalo, certamente são controles fundamentais na especificidade climática desta cidade.

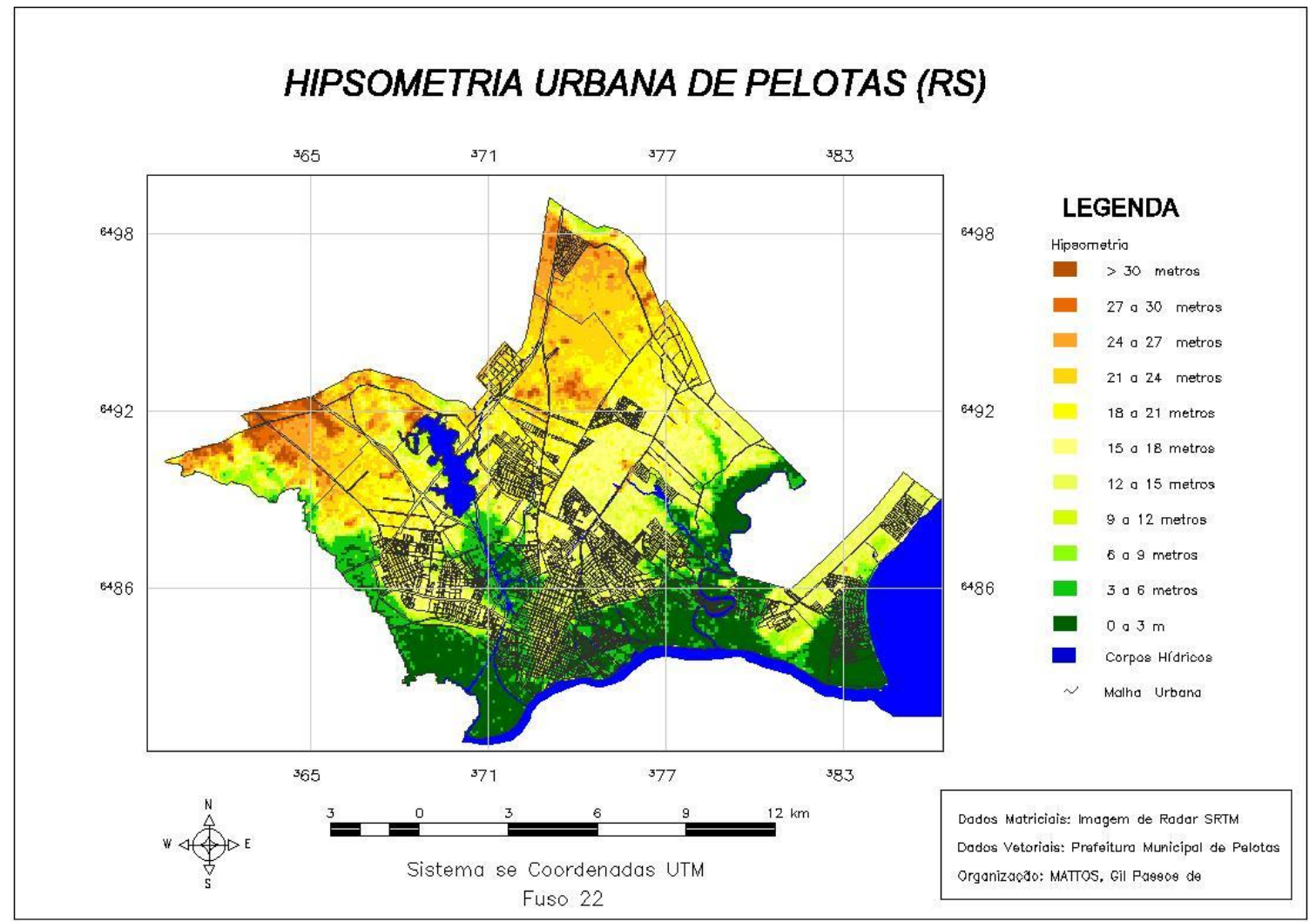

Figura 3

Mapa hipsométrico da área urbana de Pelotas. 
A altimetria na área de estudo varia entre dois metros na margem do Canal de São Gonçalo a vinte na porção norte da área efetivamente urbanizada, ainda que no perímetro urbano se encontrem áreas de altitude superior a 30 metros. A topografia, não pode ser considerada um controle essencial na definição de diferenciações climáticas intra-urbanas porque não é relevante o efeito de orientação de vertentes, fundamental na maior ou menor recepção da radiação, nem o de canalização físico-natural de vento, porém, observam-se no contexto da cidade alguns baixios que podem se tornar áreas de acúmulo de ar frio, em dias de inverno sem vento.

Quanto ao controle mais marcante do clima local - a proximidade da água -, destacamos na figura os principais corpos e cursos d'água bem como uma faixa de 100 metros em torno dos mesmos que consideramos ser área de maior umidade. Distinguem-se na figura 4, o Canal de São Gonçalo ao Sul, o canal e a Barragem Santa Bárbara e o canal do Pepino. Os três últimos já são derivações das formas naturais, por intervenção humana.

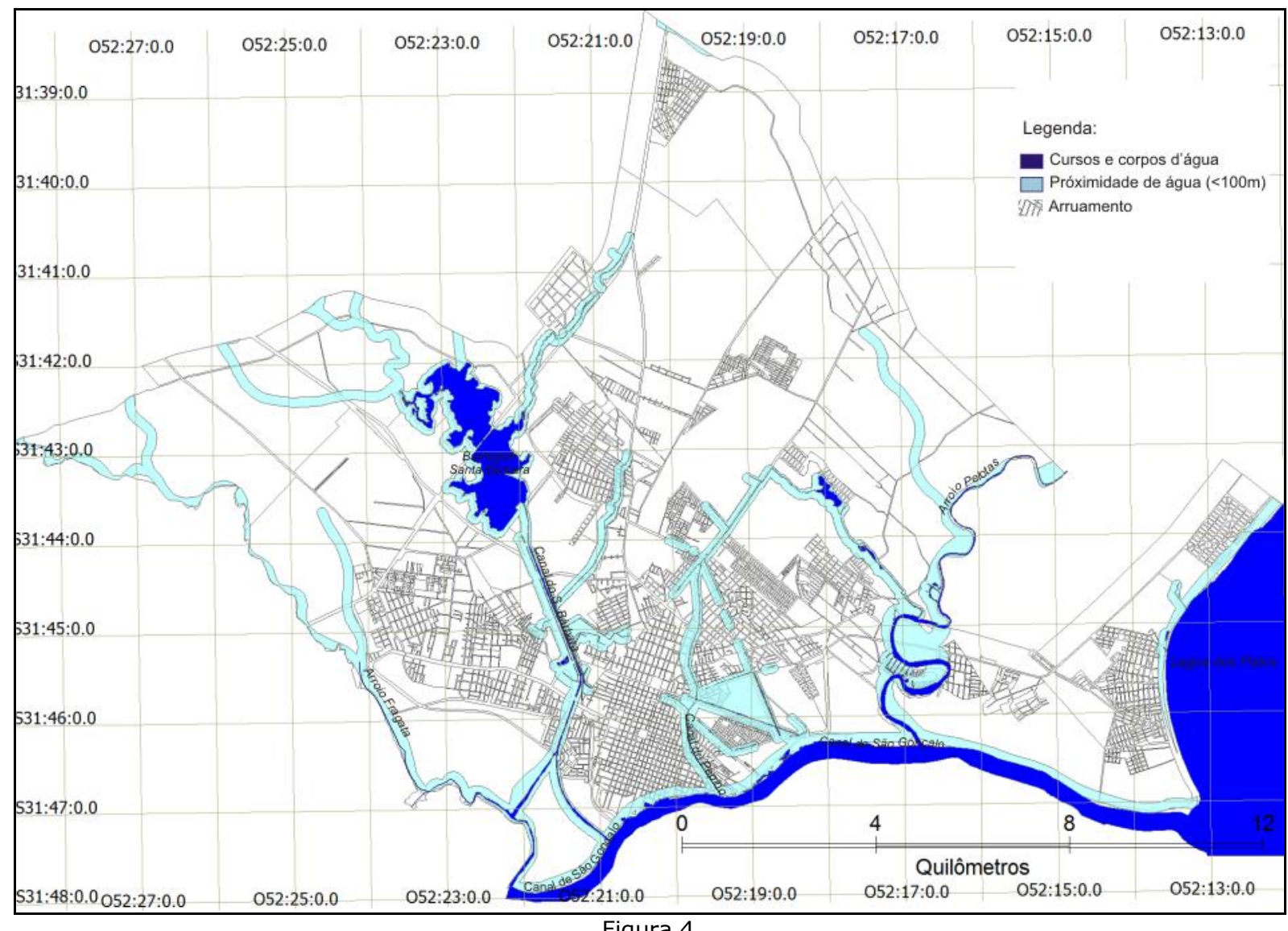

Hidrografia aparente e áreas influenciadas pela umidade dos cursos e corpos d'água na área de estudo

Como cidade média, Pelotas oferece um leque bastante largo de comércios e serviços especializados, estando assim em interação constante com as áreas coloniais e cidades menores do espaço regional a ela ligado; também recebe constantemente migrantes de cidades menores ou da zona rural, que aí se fixam. Assim, o espaço intraurbano de Pelotas se caracteriza por um centro funcional bem individualizado e uma periferia dinâmica, evoluindo segundo um modelo bem parecido com o das grandes cidades, isto é, através da multiplicação de novos núcleos habitacionais periféricos, bastante dependentes do centro funcional. O Centro, durante o dia, concentra pessoas, veículos e usos intensos da terra. Ainda assim, Pelotas não apresenta crescimento vertical significativo, expandindo-se por aglomerações residenciais horizontalizadas que fazem o tecido urbano se dissolver para limites cada vez mais amplos. A partir do centro urbano tradicional (Praça Coronel Pedro Osório), a cidade se espraia por cerca de $7 \mathrm{~km}$ para o norte (bairro Três Vendas), $6 \mathrm{~km}$ para o oeste (bairro Fragata), 1,5 km para o sul 
(Porto), $4 \mathrm{~km}$ para leste (bairro Areal), sem considerar o Bairro Laranjal à beira da Lagoa dos Patos, que fica ainda $11 \mathrm{~km}$ mais distante. Assim o perímetro urbano de Pelotas apresenta uma ocupação horizontal extensa $\left(192.65 \mathrm{~km}^{2}\right)$, compacta próximo aos eixos viários principais e menos densa nos interstícios, onde ainda são freqüentes os alagadiços e áreas de uso agrícola (Figura 5).

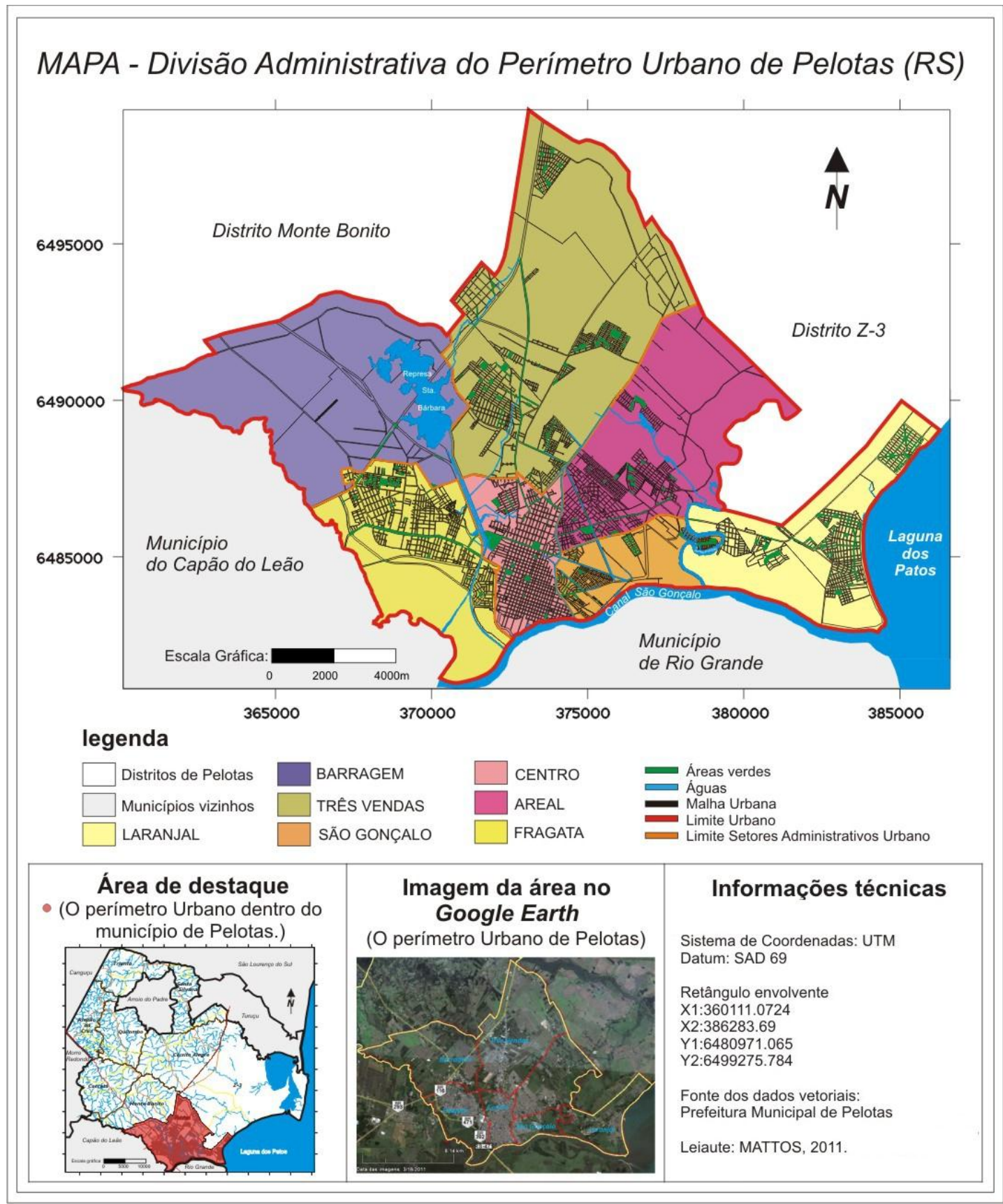

Figura 5

A configuração do perímetro urbano de Pelotas

A densidade demográfica no perímetro urbano que em 2010 apresentava uma média de $8949 \mathrm{hab} / \mathrm{km}^{2}$, em nível de detalhe, apresenta significativas variações. Encontram-se setores censitários com alta densidade (acima dos $18.000 \mathrm{hab} / \mathrm{km}^{2}$ ), de localização periférica, vinculados a bairros com sub-habitações ou a conjuntos habitacionais de até quatro pisos, caracterizados por domicílios com baixos ingressos econômicos, destacando-se áreas nos bairros Navegantes, Balsa, Dunas, Pestano, Getúlio Vargas, Guabiroba e Lindóia. Além destes, ainda que com menor densidade, foram identificadas, pelo IBGE no censo de 2010, seis aglomerados subnormais, que são "conjuntos com, no mínimo, 51 unidades habitacionais carentes de serviços públicos essenciais ocupando, ou 
tendo ocupado em período recente, terreno de propriedade alheia (pública ou particular) e estando dispostas, em geral de forma desordenada e densa" (IBGE,2010). A Secretaria Municipal de Habitação de Pelotas oficializou, em outubro de 2011, a existência de 40mil famílias vivendo em habitações precárias na cidade (Diário Popular. 04/10/2011). Se cada uma destas famílias computa em média com três pessoas, $36 \%$ da população de Pelotas vive, atualmente, em habitações precárias. Ainda assim, há os setores que apresentam densidades menores que $5.000 \mathrm{hab} / \mathrm{km}^{2}$ que estão localizados, em geral, em bairros residenciais nos quais os chefes de domicílio apresentam os ingressos econômicos mais altos.

Pelotas não tem a mesma complexidade urbana das metrópoles brasileiras já estudadas em termos de clima urbano; quanto ao uso do solo, pode-se dizer que ela apresenta uma ocupação bem menos intensiva do que aquelas. Esta cidade teve na sua gênese a predominância de terrenos unifamiliares, com casa, pátio e jardim ao fundo, ou seja, uma baixa ocupação. No entanto, este padrão, vem sendo aos poucos substituído tanto na área central, por um adensamento de construções nos outrora pátios interiores, como na periferia, pela proliferação de conjuntos habitacionais de alta densidade de ocupação. Também, há áreas de crescimento vertical e, outras de amplos prédios, que outrora abrigavam funções industriais e, atualmente, são, em sua maioria, depósitos ou entrepostos comerciais. As áreas residências apresentam-se, em geral, muito compactas, com casas junto à rua e sem jardim. A arborização urbana, afora a dos corredores verdes das grandes avenidas e a das praças, é pouco frequente. Em termos de pavimentação, o trabalho de campo nos mostrou que, saindo dos eixos viários estruturadores, poucas são as ruas calçadas ou asfaltadas nas Regiões Administrativas do entorno daquela do Centro, predominando nestas o pavimento solto.

Quando se considera todo o perímetro urbano, a ocupação é bem diversificada. Há uma área que circunda a cidade de noroeste a leste, considerada como urbana pelo Plano Diretor de 2008, destinada em princípio às atividades agrosilvopastoris, bem como às atividades de extração (areia e argila), mas marcada pela paulatina penetração do rural pelo urbano. Assim, também para a realidade de Pelotas, distinguir o urbano do rural para estudos de ilha de calor está se tornando difícil, porque muitas superfícies, ainda que distantes do centro da cidade encontram-se muito alteradas devido às necessidades urbanas.

\section{Resultados e discussões}

Com base nas categorias e unidades propostas por Stewart e Oke (2009), bem como considerando os mapeamentos realizados Prefeitura Municipal de Pelotas para o Plano Diretor de Pelotas de 2008, as visitas virtuais via Google Earth e o esquadrinhamento da área de estudo através de levantamentos de campo, definimos uma classificação prévia de potenciais unidades homogêneas.

Assim, para a categoria urbano propriamente dita, definimos as seguintes unidades: I Densamente urbanizada com prédios residenciais e comerciais confinados ou muito próximos de diferentes alturas, II - Densamente urbanizada com prédios residenciais e comerciais confinados ou muito próximos de até 4 andares, III - Habitação de um ou dois pavimentos muito compacta, IV- Blocos residenciais de 4 ou mais andares, V- Área industrial de hipermercados e depósitos, VI- Residencial de baixa densidade de ocupação com casas ou sobrados em terrenos com jardim, VII- área de sub-habitação (assentamentos informais), VIII- Corredores Verdes e Praças e IX - Instituições (aeroporto, universidades, centros de exposição) em meio a terrenos amplos. Para a categoria que chamamos paisagem mista, individualizamos a unidade $X$ - Povoamento disperso. Para a categoria que definimos como agrícola, identificamos: XI- Cultivos inundados, XII- Florestas cultivadas, XIII - Cultivos não inundados e XIV- solo exposto; e, por fim, para a categoria que definimos como natural, as unidades: XV- banhados, XVI- Floresta nativa, XVII - campos e pastagens e XVIII - corpos d'água. Posteriormente, quando da análise da imagem de satélite ainda foi acrescentada a esta última categoria a unidade XIX - Dunas ou areias.

A preparação da setorização geográfica da cidade nestas unidades relativamente homogêneas aptas a servirem de base para o estudo de diferenciação climática intraurbana demandou os seguintes materiais: Imagem do satélite Ikonos II - PSM de 
29/03/2009 (resolução de $1 \mathrm{mx1m),} \mathrm{Imagem} \mathrm{do} \mathrm{Satélite} \mathrm{SPOT} \mathrm{14/04/2005} \mathrm{(20m),} \mathrm{Malha}$ dos Setores Censitários Urbanos do IBGE de 2010, Mapa das Quadras do Perímetro Urbano de Pelotas, fornecido pela Secretaria Municipal de Gestão Urbana e os programas Spring 5.1 e Google Earth.

No programa Spring 5.1 realizamos a montagem de um banco de dados geográficos para o qual importamos as imagens de satélite e as bases cartográficas já existentes. Depois dos procedimentos de melhoria de contraste e de criação de composições coloridas das imagens passamos aos processos de classificação das imagens. Trabalhamos com duas formas de classificação uma mais geral baseada nas imagens SPOT de menor resolução e a outra mais específica para as áreas efetivamente urbanas baseada na Imagem Ikonos; posteriormente a segunda classificação foi sobreposta à primeira. Utilizamos esta estratégia porque não foi possível chegar a uma classificação razoável de unidades espaciais urbanas através de classificação supervisionada, nem pixel a pixel nem por regiões. Na classificação pixel a pixel, após a criação de um conjunto de amostras de treinamento que associam determinado conjunto de células da imagem a uma classe de ocupação da terra considerando suas características espectrais, utilizam-se algoritmos cujo reconhecimento de padrões espectrais na imagem se faz com base nas estatísticas das amostras colhidas (MOREIRA, 2011, p.236-237). Os classificadores por regiões utilizam, além da informação espectral do pixel, a de seus vizinhos. A segmentação da imagem em regiões, procura simular o comportamento de um foto intérprete ao reconhecer áreas homogêneas dentro da imagem. Posteriormente, estas regiões são utilizadas como amostras de treinamento às quais se associa uma classe de ocupação da terra e servem como referência para o reconhecimento de padrões na imagem como um todo (MOREIRA, 2011, p.237). A dificuldade em aplicar estes classificadores em nosso estudo, deveu-se a heterogeneidade do comportamento espectral dos alvos na imagem de alta resolução na área urbana. Para as áreas agrícolas e físico-naturais, nas quais os padrões espectrais variam menos no espaço, foi possível a utilização da classificação por reconhecimento desses padrões em uma imagem SPOT.

Em função do exposto, para identificar as unidades climáticas intra-urbanas com base na imagem IKONOS empregamos a interpretação visual na tela do computador, que consistiu na delimitação das feições sobre a imagem como polígonos e posterior associação dos mesmos a uma das dezenove classes. Neste caso, além do comportamento espectral, foram utilizadas outras informações como padrão, textura, tonalidade, sombra, forma e tamanho das feições encontradas na imagem, bem como o reconhecimento in loco. Este processo de interpretação e rotulação de cada área foi bastante demorado e a classificação obtida foi superposta àquela de maior generalização elaborada anteriormente para a obtenção do mapa temático de Potenciais Unidades Climáticas (Figura 6). Portanto, houve junção das abordagens visual e digital, para chegarmos a este mapeamento, com forte interação dos analistas. 


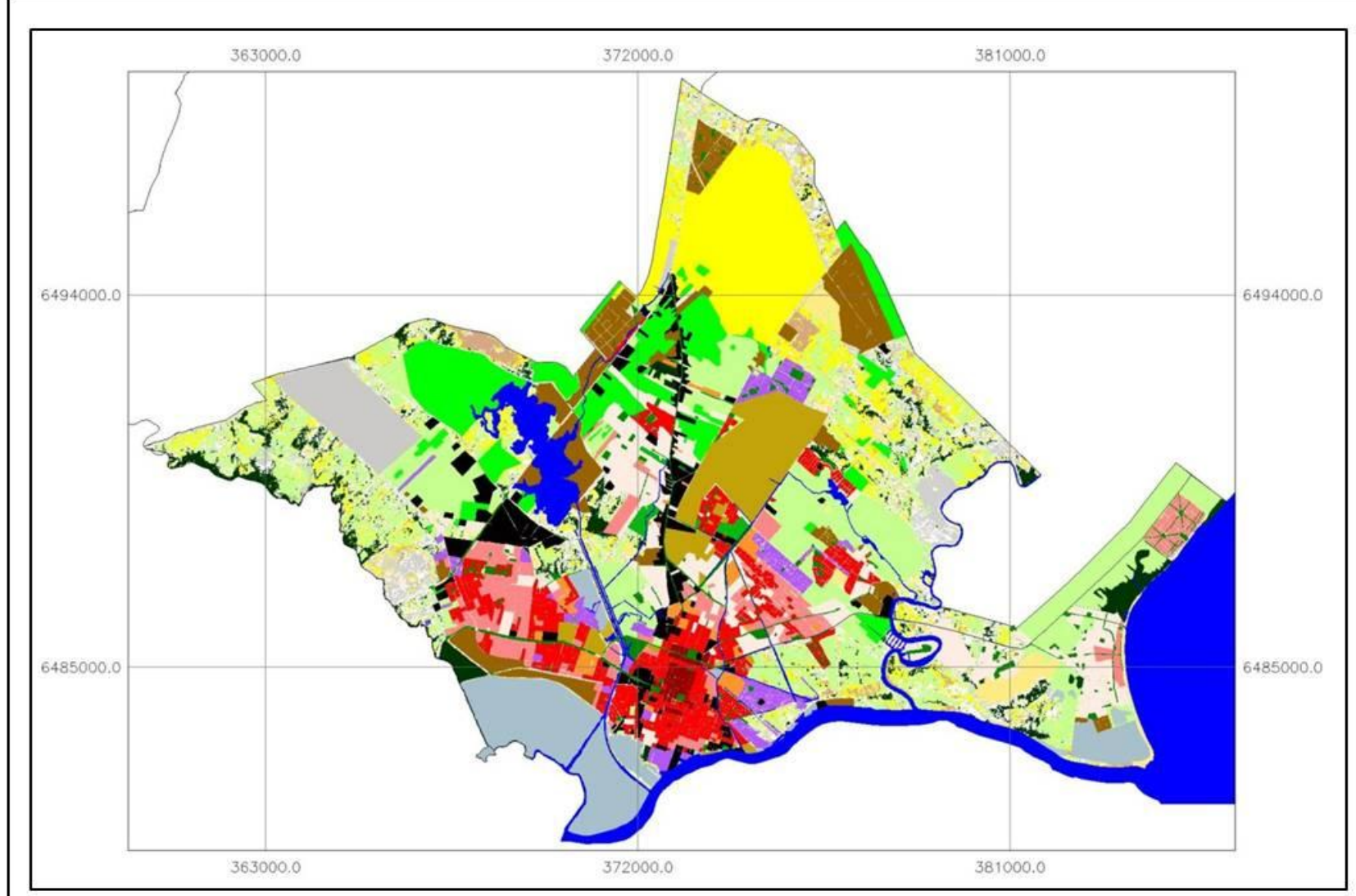

\begin{tabular}{|c|c|c|}
\hline \multicolumn{3}{|c|}{ Legenda } \\
\hline Cor & Classe & Caracteristicas \\
\hline & 1 & Prédios Altos \\
\hline 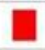 & II & Prédios e casas muito compactas \\
\hline 口 & III & Casas compactas \\
\hline 口 & IV & Blocos residências sup. a 4 andares \\
\hline & v & Áreas Industriais e hipermercados \\
\hline 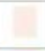 & VI & Áreas com casas com grandes jardins \\
\hline $\mathbf{0}$ & VII & Áreas de sub-habtação \\
\hline 뭄 & VIII & Praças, parques e boulevares \\
\hline 口 & IX & Grandes áreas institucionais, ex: Aeroportc \\
\hline 口 & $x$ & Povoamento disperso \\
\hline 口 & $\mathrm{XI}$ & Cultivo irrigado \\
\hline$\square$ & XII & Floresta cultivada \\
\hline [1] & XIII & Área de cultivo variado \\
\hline 口 & XIV & Solo Exposto \\
\hline 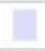 & $\mathrm{xV}$ & Banhado \\
\hline & $X V I$ & Floresta Nativa \\
\hline & XVII & Campos \\
\hline - & XVIII & Águas \\
\hline 1 & IXX & Areias \\
\hline
\end{tabular}

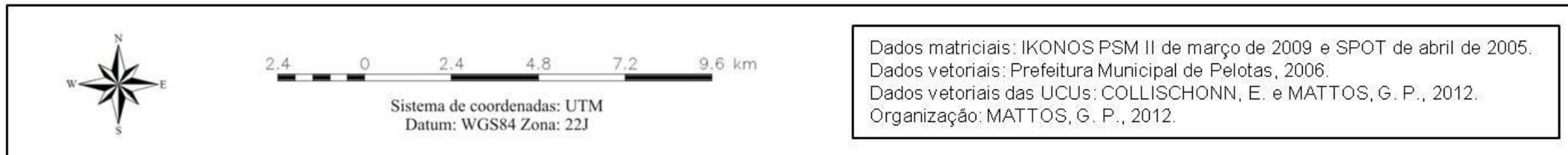

Figura 6

Potenciais unidades climáticas urbanas de Pelotas 
O resultado da aplicação da metodologia de Steward e Oke (2009) ao perímetro urbano de Pelotas na forma de um mapa de unidades climáticas urbanas indica que, com certeza, não se pode esperar para esta cidade um padrão espacial de isotermas típico de áreas urbanas mais compactas (Figura 7), como a do modelo de Oke, 1982.

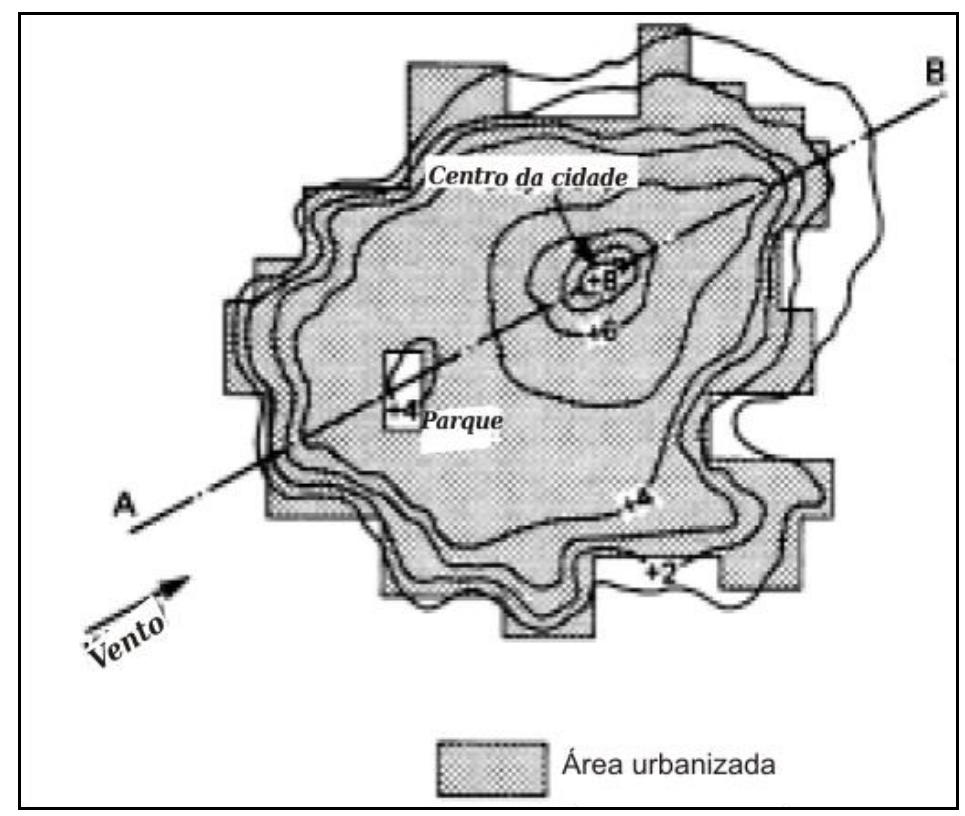

Figura 7

Padrão espacial de isotermas ilustrando a ilha de calor para uma grande cidade em noites de tempo claro e calmo

(Fonte: OKE, 1982).

Em Pelotas, o próprio sítio urbano dificultou uma ocupação urbana como a representada no modelo. Além disso, pelo que se observa no mapa das Unidades Climáticas Urbanas (Figura 6), deve-se esperar que as isolinhas de temperatura e "ilhas" de umidade se pareçam com os contornos da topografia criada pela urbanização, com alguns picos de calor, platôs extensos com temperatura e umidade análogas entremeados de bolsões de ar frio, aliadas a ilhas úmidas ou secas, dependendo a época do ano. Caso as feições de isolinhas estejam co-localizadas com manchas de maior ou menor desenvolvimento urbano, como enclaves de zonas comerciais e de serviços, conjuntos habitacionais, hipermercados, fábricas, parques, áreas abertas ou água, elas estarão refletindo fielmente a estrutura espacial. Em ambientes com solo agrícola exposto no verão, talvez se configure um platô quente em alguns horários do dia.

\section{Considerações finais}

A expansão rápida da urbanização em Pelotas que foi incorporando as superfícies agrícolas ou físico-naturais que a circundavam, preenchendo as áreas intersticiais antes ocupadas por coberturas naturais e alongando a trama urbana através das principais vias de acesso, demonstra o fim do caráter mais compacto, monocêntrico e socialmente mais homogêneo que caracterizou esta cidade até os anos 1980. A crescente heterogeneidade e segregação socioambiental das paisagens urbanas nesta cidade representa também o aumento da segregação socioespacial de seus habitantes e cada vez maior dependência da qualidade ambiental ao nível de renda. A delimitação de potenciais unidades climáticas possibilitou reconhecer onde as alterações da superfície urbana são mais significativas e onde as áreas verdes tem reduzido seu tamanho ou se fragmentado, auxiliando-nos a definir locais nos quais seria interessante instalar instrumentos para medir a variação temporal da temperatura, umidade relativa e vento ao longo do dia, por fim, formular sugestões para melhorar a qualidade ambiental da cidade de Pelotas. 
Steward e Oke (2009) nos ofereceram um sistema para a classificação de zonas térmicas na camada de dossel urbano, logicamente estruturado e ilustrado por uma representação gráfica, que o tornou aplicável utilizando técnicas de processamento de imagens de satélite em Sistema de Informações Geográficas e reconhecimento de campo. Utilizando os princípios propostos por este sistema de classificação, chegamos a dezenove potenciais unidades climáticas diferenciadas no perímetro urbano de Pelotas. Numa segunda análise, integrada com os resultados dos levantamentos de campo de temperatura, umidade e vento, espera-se chegar a um mapa de síntese que identifique um menor número de unidades climáticas intra-urbanas, bem como, as áreas de drenagem de ar frio e as áreas de renovação do ar.

\section{Nota}

Este trabalho é parte do Projeto "Clima urbano/conforto térmico e condições de vida na cidade de Pelotas/RS", que contou com bolsa auxílio recém-doutor da FAPERGS (Fundação de Apoio a Pesquisa do Estado do Rio Grande do Sul), entre agosto de 2010 e dezembro de 2011.

\section{REFERÊNCIAS}

.MATTOS, G. P.; MAIO, B. R.; FELIX, L. S.; TAVARES, D. H. Um estudo exploratório do clima urbano, no bairro centro de Pelotas (RS). In: IV Encontro Sulbrasileiro De Meteorologia, 4., 2011, Pelotas. Anais... Pelotas: UFPel, 2011.

.MENDONÇA, F. Clima e Planejamento urbano em Londrina - proposição metodológica e de intervenção urbana a partir do estudo do campo térmico. In: MENDONÇA, F.; .MONTEIRO, C. A. F. (Org) Clima urbano. São Paulo: Contexto, 2003.

.MONTEIRO, C. A. F. Teoria e Clima Urbano. São Paulo: USP, 1976.

.MONTEIRO, C. A. F. Por um suporte teórico e prático para estimular estudos geográficos de clima urbano no Brasil. Geosul, Florianópolis: Edufsc, n. 9, ano V, p. 7-19, 1990a.

.MONTEIRO, C. A. F. Adentrar a cidade para tomar-lhe a temperatura. Geosul, Florianópolis: Edufsc, n. 9, ano V, p. 61-79, 1990b.

.MONTEIRO, C. A. F. A cidade como processo derivador ambiental e estrutura geradora de um

"clima urbano". Geosul, Florianópolis: Edufsc, n. 9, ano V, p. 80-114, 1990c.

.MOREIRA, M. A. Fundamentos do sensoriamento remoto e metodologias aplicadas. 4. Ed. Viçosa: Editora UFV, 2011.

.OKE, T. R. The energetic basis of the urban heat island. Quarterly Journal Royal Meteorological Society, 108, 1982, p. 1-24.

.OKE, T.R., Initial Guidance to Obtain Representative Meteorological Observations at Urban Sites. IOM Report No.81, WMO/TD. No. 1250. World Meteorological Organization, Geneva, 2006. Disponível em < http://www.wmo.int/pages/prog/www/IMOP/publications/IOM-81/UrbanMetObs.pdf> Acesso em Mai. 2011.

.PELOTAS tem 40 mil famílias em habitações precárias. Diário Popular, Pelotas, 4 out. 2011. .PREFEITURA MUNICIPAL DE PELOTAS - Lei 5.502, de 11 de setembro de 2008. III Plano Diretor Municipal. Pelotas: Câmara Municipal, 2008. Disponível em <http://www.pelotas.com.br/politica_urbana_ambiental/planejamento_urbano/> Acesso em 12 Mar. 2010.

.STEWART, I.D., and T.R. OKE, 2009. Classifying urban climate field sites by "local climate zones" the case of Nagano, Japan. The seventh International Conference on Urban Climate, 29 June - 3 July 2009, Yokohama, Japan. Disponível em <http://www.ide.titech.ac.jp/ icuc7/extended_abstracts/pdf/385055-1-090515165722002.pdf> Acesso em 12 Mar. 2010.

.TARIFA, J. R. ; ARMANI, G. Os climas urbanos. In: TARIFA, J. R.; AZEVEDO, T. R. Os climas na cidade de São Paulo. São Paulo: Pró-Reitoria de Cultura e Extensão da Universidade de São Paulo. Laboratório de Climatologia da Faculdade de Filosofia, Letras e Ciências Humanas, 2001. (Geousp - Coleção Novos Caminhos, 4)

Sites pesquisados:

IBGE - http://www.ibge.gov.br/ 